\title{
An Assessment of the Impacts of Agro- Ecological Practices towards the Improvement of Crop Health and Yield Capacity: A Case of Mopani District, Limpopo South Africa
}

\author{
Tshilidzi C. Manyanya, Nthaduleni S. Nethengwe, Edmore Kori
}

\begin{abstract}
Agro-ecology has emerged as a front runner in food security and sovereignty, with the UNFCCC and FAO advocating its global adoption. Agro-ecological implementation is theorised to increase crop health and yield by $3-10 \%$ in a space of $3-10$ years. This study aimed to assess the practicality and validity of these assumptions using mainly GIS and remote sensing. Adopting a mixture of Ex-post-facto and Experimental designs necessitated the presence of a control element. Each agro-ecological farm was thus assessed and compared with a conventional farm in the same geographical conditions. Crop health was assessed using satellite images analysed through ArcGIS to produce NDVI and Re-classified outputs whereas yield was calculated from production records. The shift in NDVI-crop ranges indicates changes in crop health over time. Crop health and yield both showed a decrease over $80 \%$ of the conventional farms and an increase over $80 \%$ of the organic farms.
\end{abstract}

Keywords - Agro-ecology, Agro-ecosystem, Anthropogenic, sustainability

\section{INTRODUCTION}

Agriculture as a global sector contributes about $14 \%$ of the total annual GHG emissions [19]. Temperature and $\mathrm{CO}_{2}$ are the two main elements associated with anthropogenic global warming and greenhouse gases [16]. The temperature- $\mathrm{CO}_{2}$ graph based on observations from the 1800s - 2000 shows a direct relationship between the two [9]. This relationship means controlling one automatically controls the other. However, the real world is not a vacuum and external factors can always alter theoretical assumptions and predictions. Agriculture has a natural symbiotic relationship with microclimates. This creates an environment where synergy and overlap occur in both climate change mitigation and adaptation strategies [3].

Tshilidzi Manyanya is with the University of Venda, Geography and GIS

Nthaduleni S. Nethengwe is with the University of Venda, Geography and GIS :

Edmore Kori is with the University of Venda, Geography and GIS
Agro-ecology has its roots in this synergy and overlap system, hence its advocacy for global adoption. Reference [7] states that agro-ecology can solve not only climate change issues but also food security and food sovereignty and ultimately improve human livelihoods.

\section{OBJECTIVES}

In light of the theoretical assumptions concerning agroecology, the main objective of this study was to assess the effectiveness of agro-ecology. This was done through assessing its impacts on crop health and yield.

\section{APPROACH}

The study followed a quantitative study guided by a mix of Ex-post-facto and Experimental research designs. The limited number of agro-ecological farms made critical case sampling the best choice of sampling technique, leading to a sample size of 10 farms. Half (5) of the farms were agro-ecological and half (5) were conventional.

Experimental research design requires for there to be a control element, which in this case was the conventional farms located in the same general location. The variables measured over the agro - ecological farm where compared to the variables measured over conventional farms for experimental control.

The study only required Landsat 7 (TM) satellite imagery and yield statistics which were acquired from the United States Geological Survey (USGS) and Farm owners respectively.

\section{Data Collection And Analysis}

\section{A. Crop Health}

Remote Sensing and GIS were the main techniques used to assess the impacts of agro-ecology on crop health and yield. Remote sensing allows for temporal and spatial assessment of any changes that result from the adoption of agro-ecological practices. The satellite images required for this part were 
acquired from the South African National Space Agency (SANSA) and the United States Geological Survey (USGS). Remote sensing provides high resolution spectral signatures for natural and cultivated land [14]. This forms the basis for the distinction between healthy and diseased crops caused by nutrient deficiency, pests and abiotic stresses [11]

1. NDVI (Normalized Difference Vegetation Index) And Re-Classification

NDVI is a numerical assessment method that is created from satellite imagery collected in the red and infra-red regions. NDVI categorises vegetation and displays it in a form of graduated colours and ranges [10]; [14]. The healthy crops appear red on the image while the stressed crops appear paler. Through NDVI the whole farm can be displayed on one output which then makes it possible to spot areas where the crops are stressed and areas of complete health.

Theoretically, NDVI values are represented as decimals ranging from -1 to 1 . Extreme negative values represent water bodies while values around zero represent bare soil. Values around $0.4 / 0.5$ represent agricultural lands, while higher values represent very healthy cultivated lands or forests [17]. NDVI was used to assess patterns in the health of the crop spatially or temporally. NDVI was performed for each of the ten sampled farms for 2013, 2014 and 2015. This was performed in ArcGIS 10.2. ArcGIS was also used to do the atmospheric correction and filtering. Re-classified (Unsupervised) NDVI images allow for the NDVI range outputs to be renamed according to what they represent on the actual land

\section{NDVI Range Floating Bars and Delta function}

The NDVI outputs ranges of different classes with agricultural lands as one of the ranges. Every range has a minimum value and a maximum value [6]. For the purposes of the study, we shall refer to the NDVI range corresponding to cultivated lands as NDVI-crop. The shift in the minimum and maximum values for NDVI-crop from 2013 through 2014 up to 2015 is what indicates crop health patterns [15].

Histogram Floating bars were used to graphically present the shifts in the NDVI-crop ranges. Floating bars are effective in assessing ranges because the entire range is plotted instead of the average which would only be a singular number. An average does not indicate the minimum and maximum values and as such, equal averages can have different minimum and maximum values [10]. The floating bars were created using the Microsoft Excel delta function. NDVI range as the dependent variable and Year as the independent variable. Floating bars introduce a Delta function into the plot. A delta function is a function which depends on the minimum and maximum values and is calculated using (1).

$$
\text { Delta }=\text { MaxValue-MinValue }
$$

Excel plots the Delta function on top of the minimum value. The top value of the Delta function is the maximum value.
This makes it possible to assess the shifts in the ranges with each year for each farm.

\section{YIELD CAPACITY}

Yield is a complicated variable to measure as it is dependent on farming methods and the size of land farmed. In this case, the yield records acquired from the farms were analysed using (2)

$$
\text { Yield }=\left[\text { total } \frac{\text { seasonal harvest }}{\text { farm area }}\right] \mathrm{in} \mathrm{Kg} / \mathrm{m}^{2}
$$

\section{RESULTS}

\section{A. Crop Health.}

The atmospherically corrected satellite images yielded the NDVI and Re-classified images displayed in Fig. 1.1 for Kuhestan farm. This shows all the NDVI ranges for all landuse types on the captured surface including farmed lands.

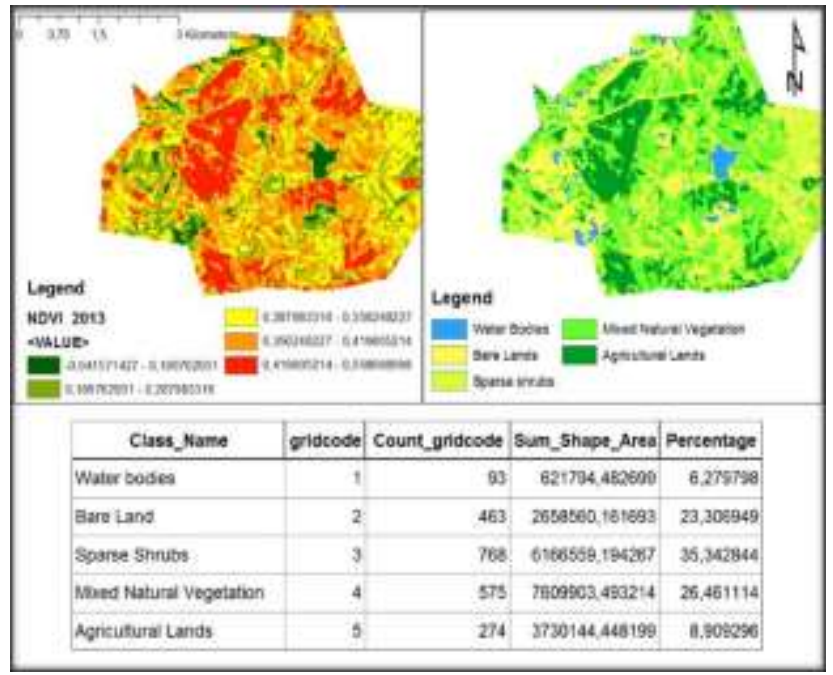

Fig. 1.1: Kuhestan Organic Farmers: NDVI and Re-class for 2013.

Similar outputs were produced for the year 2014 and 2015 respectively. The most important range is the range for cultivated lands as it is the one that indicates changes in crop health over time. The NDVI ranges for 2013, 2014 and 2015 are shown in the stacked bar graph Fig 1.2. created using Microsoft Excel's Delta function.

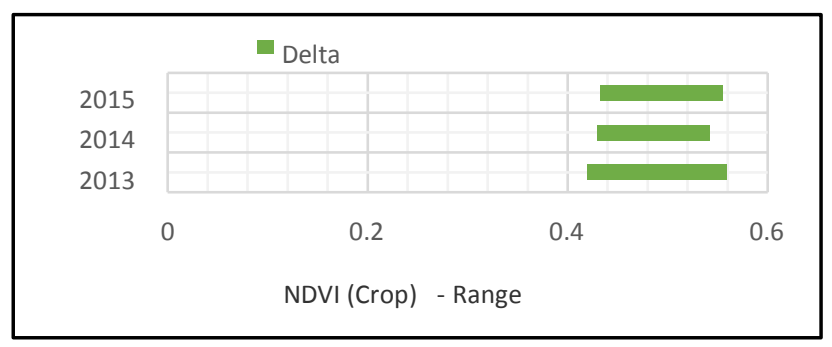

Fig. 1.2: Kuhestan farm (O5): NDVI ranges for Crops

As per the comparative aspect of this research, the same analysis had to be done on Kuhestan Farm's conventional 
counterpart, which was Bosveld Citrus. Shown in Fig. 1.3. is the NDVI and Re-classified output for Bosveld Citrus.

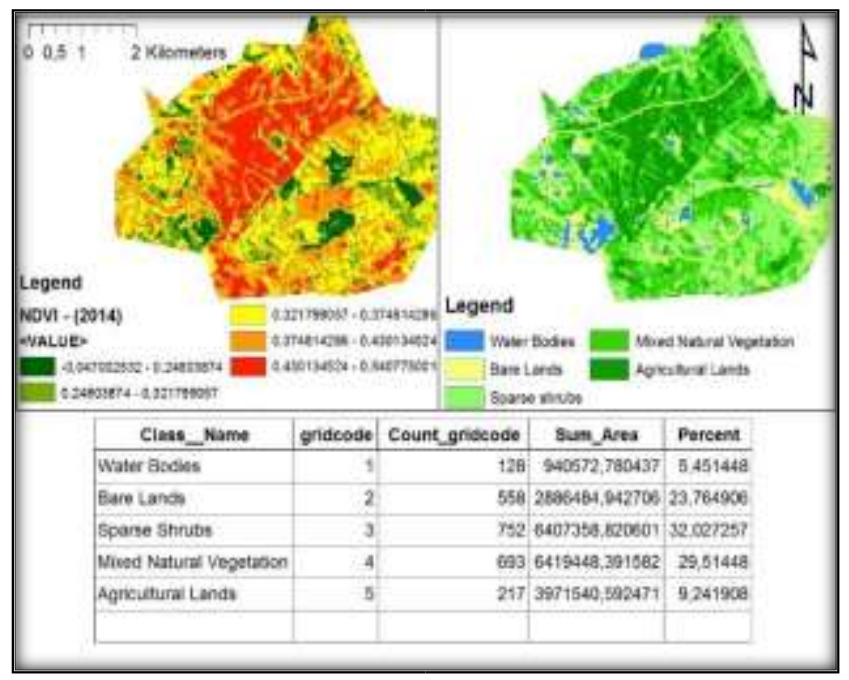

Fig. 1.3: Bosveld Citrus NDVI and Re-classified for 2013

The NDVI crop ranges for Bosveld Citrus are plotted on the Stacked bar Fig. 1.4 similarly to Kuhestan in Fig. 1.2.

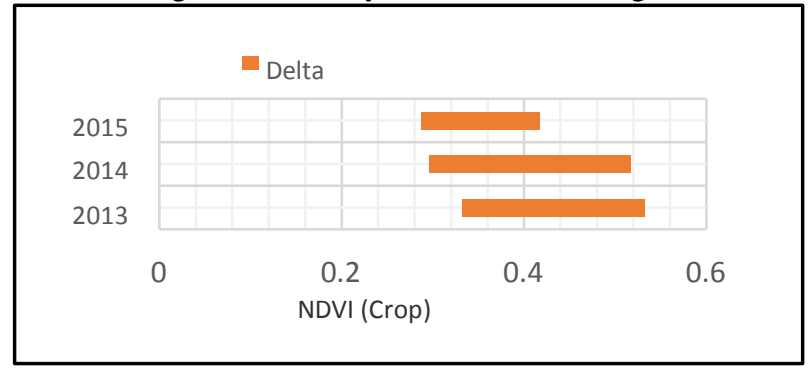

Fig. 1.4: Bosveld Citrus (C5): NDVI ranges for Crops

The rest of the farms were similarly analysed and

NDVI and Re-classified plots were created. Plotted in Fig 1.5 are the NDVI crop ranges for the remaining 8 farms over the period $(2013-2015)$.

Similar to Fig. 1.2 and 1.3, the Delta functions of each farm are plotted in their own individual colour.

The Delta function is a representative of both the minimum and the maximum values but it is not a mean value. The delta function is thus more representative than a mean because it is a range rather than a single value mean. Stacking the NDVI ranges in succession indicates any kind of patterns that would emerge. The direction of the plot indicates the direction of the relationship if one exists at all. This works similarly to a trendline analysis which performs an internal regression and outputs regression values.

Initially, through a visual observation of the plot, a sinusoidal pattern can be spotted. Visual observation increases the chances of a Type 1 error. Thus a detailed examination of the output is needed. This is given by the individual gradients of the stacked bars for each farm. Alon Mosaic, Makosha and Bombyx show an overall increasing pattern, indicating a positive gradient. ZZ2, Bavaria, and Mabunda show an overall decreasing pattern, indicating a negative gradient. Fig. 1.2 and Fig. 1.3 show Kuhestan to be increasing and Bosveld to be decreasing. This means that $80 \%$ of the Agro-ecological farms show patterns of an increase in crop health and $80 \%$ of the conventional farms show patterns of a decrease in crop health.

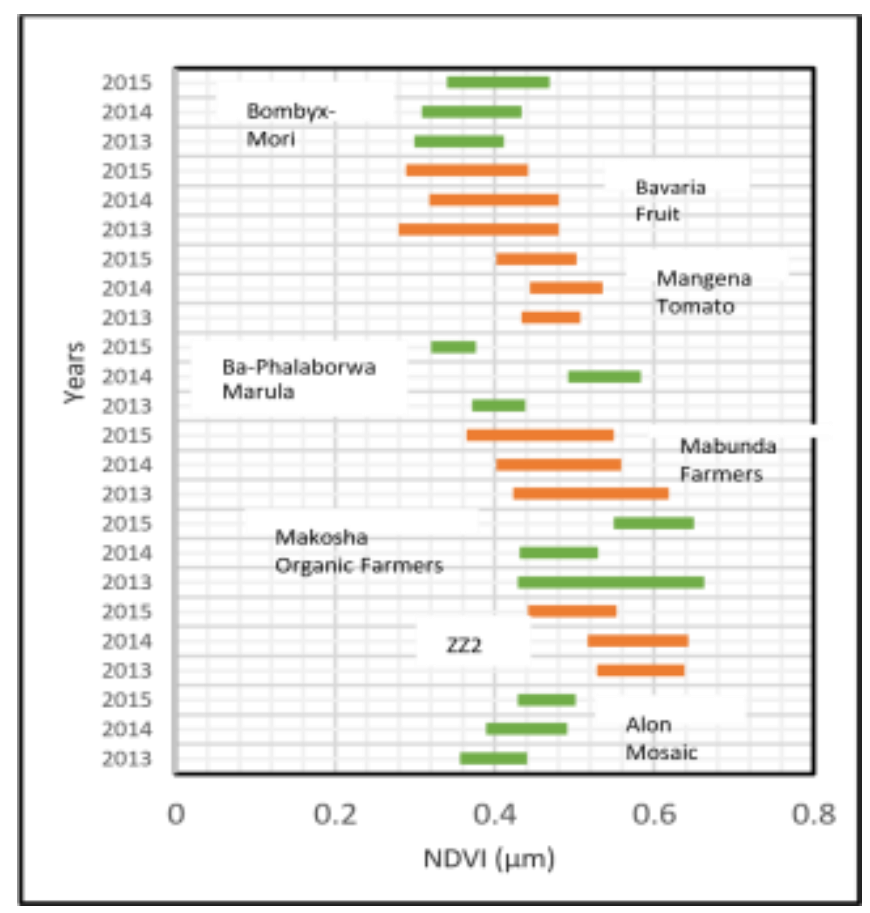

Fig. 1.5: NDVI (Crops) stacked Bars

\section{B. Individual Farm Yield Patterns Assessment}

Yield was calculated using Equation 1.2 and is shown as percentages of a total of $100 \%$ for each farm. Presenting the yield as percentages was due to some of the farmers' discomfort with having the actual seasonal yield published for unknown reasons. This challenge was overcome by aggregating the seasonal yield for each of the three years to a perfect percentage of $100 \%$. This was done for each of the farms individually. Instead of representing the yield as actual figures, the yield of each year presented as a percentage of the total yield of the entire period aggregated at $100 \%$. This also provides an advantage because it is easier to calculate the percentage variance of the yield from 2013 through 2014 to 2015. The yield percentages are presented on the stacked bar graph in Fig. 1.4.

Fig. 1.6 reveals that Bombyx-Mori has had an increase of $1.9 \%$ over the period from 2013 to 2015. Despite the increase in yield, it is still a $0.1 \%$ decrease as compared to the yield of 2014. Bavaria which is found in the same general location has had a slight decrease of $1.2 \%$. This is also a decrease of $0.8 \%$ from the yield of 2014. The rest of the yield percentage variances over the period are presented in TABLE I. 


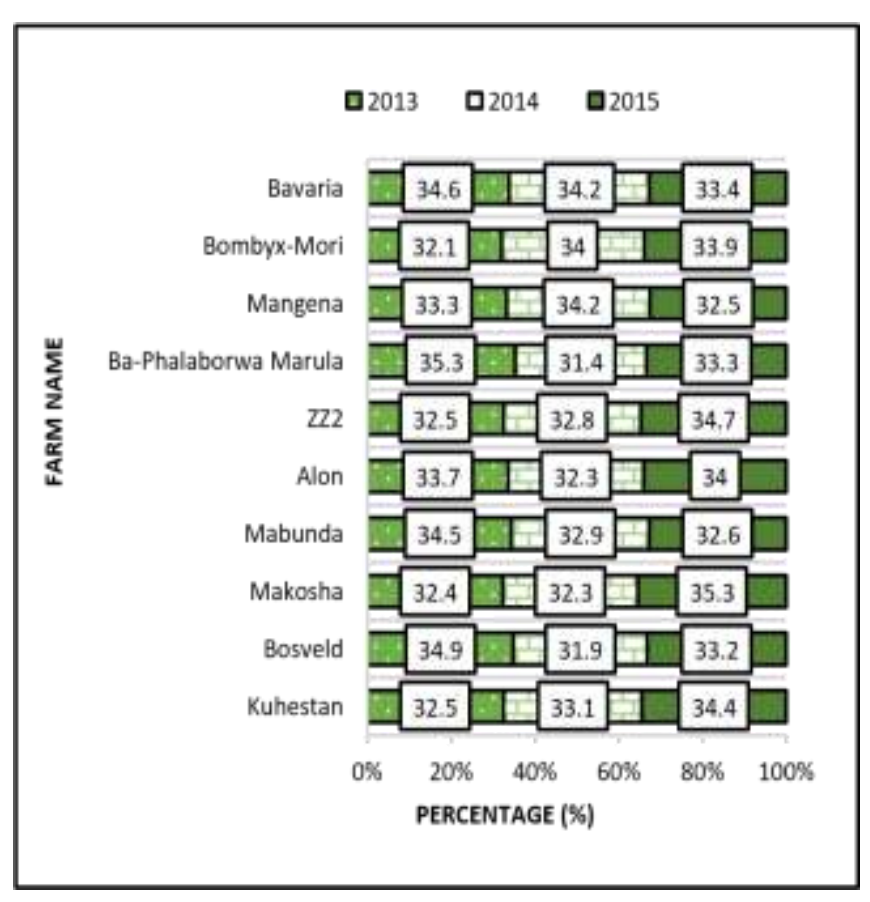

Fig. 1.6: Yield Percentages.

\begin{tabular}{|c|c|c|c|}
\hline \multicolumn{4}{|c|}{$\begin{array}{c}\text { TABLE I } \\
\text { YIELD PERCENTAGE VARIANCE }\end{array}$} \\
\hline Farm Name & $\begin{array}{l}2013- \\
2014\end{array}$ & $\begin{array}{l}2014- \\
2015\end{array}$ & $\begin{array}{l}\quad \text { Overall } \\
\text { Percentage } \\
\text { variance }\end{array}$ \\
\hline Kuhestan & 0,6 & 1,3 & 1,9 \\
\hline Bosveld Citrus & -3 & 1,3 & $-1,7$ \\
\hline $\begin{array}{l}\text { Makosha Organic } \\
\text { farmers }\end{array}$ & $-0,1$ & 3 & 2,9 \\
\hline Mabunda farmers & $-1,6$ & $-0,3$ & $-1,9$ \\
\hline Alon Mosaic & $-1,4$ & 1,7 & 0,3 \\
\hline ZZ2 & 0,3 & 1,9 & 2,2 \\
\hline $\begin{array}{l}\text { Ba-Phalaborwa } \\
\text { Marula }\end{array}$ & $-3,9$ & 1,9 & -2 \\
\hline $\begin{array}{l}\text { Mangena Tomato } \\
\text { farm }\end{array}$ & 0,9 & $-1,7$ & $-0,8$ \\
\hline $\begin{array}{l}\text { Bombyx-Mori silk } \\
\text { farm }\end{array}$ & 1,9 & $-0,1$ & 1,8 \\
\hline Bavaria fruit estate & $-0,4$ & $-0,8$ & $-1,2$ \\
\hline
\end{tabular}

TABLE I, reveals fluctuations in yield for both conventional and agro-ecological farms. Based on the research stages that came before this section, some of these patterns are expected. Kuhestan, Bombyx, Alon Mosaic and Makosha display an expected pattern of an increase in yield over the period 2013 - 2015. However, despite this overall increase in yield, there is very little consistency over the entire period. Makosha has a decrease of $0.1 \%$ from 2013 - 2014, followed by a drastic increase of $3 \%$ from 2014 - 2015. Alon Mosaic also follows the same pattern of an initial decrease followed by an increase. The overall increase is expected due to the predictions and proposals by [4]. Ba-Phalaborwa is the only agro-ecological farm that shows an unexpected outcome, the overall yield has decreased by $2 \%$ following an initial decrease of $3.9 \%$.

Most of the conventional farms show a decrease in yield. $\mathrm{ZZ2}$ is the only farm that has irregular patterns in yield. It has an overall increase of $2.2 \%$ following an increase of $1.9 \%$ after an initial increase of $0.3 \%$. This is contrary to what according to the theoretical body of knowledge should occur on a conventional farm. Yield fluctuations are still observed in conventional farmers over the period despite the overall decrease, which is expected.

The majority of agro-ecological farms (80\%) show an increase in yield over the period while the majority $(80 \%)$ of the conventional farms show a decrease in yield

\section{DisCUSSIONS AND CONCLUSIONS}

Crop health does not only depend on the activities which take place on a farm such as pest control, farming methods and fertilisation. There is a dependence on external factors such as the quality of irrigation water, climatic conditions among others. All these internal and external factors influence the soil properties, which then influences crop health [1]; [7]. Focusing on agro-ecological farms assumes no input of chemical fertilisers and pesticides for all the organic farms. This means they cannot be used to explain the fluctuations in the patterns revealed by the crop health analysis.

The stacked bar graph in Fig. 1.5 reveals unexpected fluctuations in the crop health of four farms over the period of 2013 - 2015. These farms are Makosha, ZZ2, Mangena and Ba-Phalaborwa Marula. Mangena and Ba-Phalaborwa Marula are located in the same general location. Mangena is a conventional farm and Ba-Phalaborwa is agro-ecological. They both show an overall decrease in crop health over the period 2013 - 2015. This is contrary to observations by references [7] and [8]. The crop health over an agro-ecological farm is expected to increase. For this reason, Ba-Phalaborwa Marula was expected to show an increase in crop health overall.

Unlike Mangena, which is also a tomato farm, ZZ2 displays opposite patterns in crop health. Being a conventional farm, the crop health is expected to decrease over the $2013-2015$ period; however, ZZ2 shows an increase. The two farms are not in the same general location; as such, the overall climatic conditions are not the similar. The availability of resources also plays a role in the overall crop health of a conventional farm. Mangena is a smaller corporation and a recently established farm whereas $\mathrm{ZZ2}$ is a major conglomerate of farms with a vast availability of resources including a team of agricultural researchers. This means that $\mathrm{ZZ2}$ has better response to potential crop health reducing temperature fluctuations [13].

Irrigation is a major contributor to crop health. This goes beyond the availability of water but also the quality of water. 
Water can bring toxins onto the farm acquired from an external source or as external inputs into the river before it reaches the farm [18]. These toxins are trapped in the soil and ultimately making their way into the crops. Bavaria fruit estate displays expected trends in crop health. Being a conventional farm, crop health is supposed to decrease as it does. NDVI and Re-class outputs reveal fluctuations in water, which may have contributed towards the decrease in crop health. Water bodies decreased from $6.9 \%$ to $5.8 \%$ over the $2013-2015$ period as shown in Appendix 1. This poses a threat to the irrigation process.

Despite Makosha displaying an expected increase in crop health, there are irregular fluctuations in the NDVI ranges, which are worth investigating. The minimum NDVI value for crop health in 2015 jumps to a value bigger than the maximum value of 2014. This is an irregularity since the ranges are usually expected to overlap. The NDVI and Re-classified outputs for both 2014 and 2015 reveal an increase in water supply provided by the adjacent river. In addition, 2015 reveals an establishment of a Dam next to the farms. This brings up a possibility that increased water supply could have increased the crop health instead of farming methods [12].

Trends in yield capacity show a similarity to those observed in crop health. Most of the farms (80\%) which have increasing temperature patterns have decreasing crop health trends and an increasing yield pattern. These are mostly agro-ecological farms. As much as this observation confirms the theoretical expected outcomes, the degree to which agro-ecology is practiced raises concerns. Without total implementation of agro-ecology from seed acquisition to trade, many of the trends, which seem to confirm literature, may have been influenced by other non-agro-ecological factors.

Mixing of methods steals reduces full economic sustainability from an agro-ecological farm. A detailed analysis would include as assessment of the labour management system and the final destination for the crop harvest. This would also include an assessment of the farm's contribution towards human livelihoods improvement [5]. A farm that produces a high yield without making contributions to human livelihoods and community engagement is not considered fully economically sustainable in agro-ecological terms [2]

\section{REFERENCES}

[1] M.A. Altieri, Agroecology: the science of sustainable agriculture. Colorado: Westview Press. 1995.

[2] M.A. Altieri, F.R. Funes-Monzote P. Petersen, 2000. "Agro-ecologically efficient agricultural systems for smallholder farmers: contributions to food sovereignty" in Agronomy for Sustainable Development, 32 ED vol $1 \mathrm{pp}: 13,2000$

[3] R. Bezner-Kerr, K.L. McGuire, R. Nigh, D. Rocheleau, J. Soluri and I. Perfecto, "Effects of industrial agriculture on climate change and the mitigation potential of small-scale agro-ecological farms" in Animal Science Reviews ED 011: Number 69.

[4] O. De Schutter, "How not to think of land grabbing: three critiques of large-scale investments in farmland" in The Journal of Peasant Studies ED 38 vol (2), 2011, pp:249- 279.

[5] C. Eghenter, Michael Dove: the banana tree at the Gate. A History of marginal peoples and global markets in Borneo. Human Ecology, ED 40 vol (1), 2012, pp. $165-166$.
[6] A.A. Gitelson, "Wide dynamic range vegetation index for remote quantification of biophysical characteristics of vegetation" in Journal of plant physiology ED $161 \mathrm{vol}$ (2), 2004, pp.165-173.

[7] S. Gliessman Agroecology: The Ecology of sustainable food systems ED 2, New York: CRC press, 2007

[8] S. Gliessman, "Agroecology and food system change" in Journal of Sustainable Agriculture, ED 35 vol (4), 2011, pp.347-349.

[9] D.V. Hoyt, The role of the sun in climate change. Oxford: Oxford University Press, 1997

[10] K. Hufkens, M. Friedi, O. Sonnentag, B.H. Braswell, T. Milliman and A.D. Richardson, "Linking near-surface and satellite remote sensing measurements of deciduous broadleaf forest phenology" Remote Sensing of Environment, ED 117, 2012, pp. 307 - 321. https://doi.org/10.1016/j.rse.2011.10.006

[11] Y. Lan, Y. Huang, W. Hoffmann, "Use of airborne multispectral imagery in pest management systems" in International agricultural engineering journal ED X, 2008, pp. 07 - 10

[12] S. Murcott, "Arsenic Contamination in the World: An International Sourcebook “ in Water Intelligence Online, ED 11, 2012, pp. 97.

[13] B.D. Patterson, D. Graham \& R. Paull, Adaptation to chilling: survival, germination, respiration and protoplasmic dynamics in low temperature stress in crop plants. Cambridge: Academic Press: 1979.

[14] P. Pinter, J. Hartfield, J. Schepers, E. Barnes, S. Moran, C. Daughtry and D. Upchurch, "Remote Sensing for Crop Management" in Photogrammetric Engineering \& Remote Sensing ED 69 vol (6), 2004, pp. 647-664.

[15] D.S. Powlson, C.M. Stirling, C. Thierfelder, R.P. White \& M.L. Jat, "Does conservation agriculture deliver climate change mitigation through soil carbon sequestration in tropical agro-ecosystems" in Agriculture, Ecosystems \& Environment, ED 220 2016, pp. 164 - 174. https://doi.org/10.1016/j.agee.2016.01.005

[16] S. Solomon, G.K. Plattner, R. Knutti and P. Friedlingstein, "Irreversible climate change due to carbon dioxide emissions" in Proceedings of the national academy of sciences Number (3), 2009, pp. 08-80. https://doi.org/10.1073/pnas.0812721106

[17] C. Unsalan and K.L. Boyer. "A system to detect houses and residential street networks in multispectral satellite images" in Computer Vision and Image Understanding, $98 \mathrm{ED}$ vol (3), 2005, pp.423-461,

[18] Z. Wang, X. Sun, C. Li, X. He \& G. Liu, "Onsite detection of heavy metals in agriculture Land by a disposable sensor based virtual instrument" in Computers and Electronics in Agriculture. 123 ED 2016, pp. 176-183.

[19] T.O. West and A.C. Mcbride, "The contribution of agricultural lime to carbon dioxide emissions in the United States: dissolution, transport, and net emissions" in Agriculture, Ecosystems \& Environment, 108 ED vol (2) 2005, pp.145-154. 